\title{
Cone-beam Computed Tomographic Analysis: Comparison of the Efficacy of Two Rotary Retreatment Systems for Removal of Filling Material from Primary Teeth Obturated with Contemporary Endodontic Sealers
}

\author{
${ }^{1}$ Camila Said Moreira, ${ }^{2}$ Frederico Canato Martinho, ${ }^{3}$ Marcella Pavanello Batista Coelho, ${ }^{4}$ Luis Roberto Manhães \\ Coutinho Júnior, ${ }^{5}$ Eduardo Galera da Silva, ${ }^{6}$ Carlos Rocha Gomes Torres, ${ }^{7}$ Ana Paula Martins Gomes
}

\begin{abstract}
Introduction: This study has used cone-beam computed tomography (CBCT) to evaluate the efficacy of two different nickel titanium (NiTi) rotary retreatment systems for removal of filling material from teeth obturated with contemporary endodontic sealers. The operative time required for removal of root filling materials was also evaluated.

Methods: Sixty root canals were randomly divided into three groups according to the sealer used for obturation: AH Plus Jet, mineral trioxide aggregate (MTA) Fillapex, and RoekoSeal Automix (RSA) (all, $n=20)$. After obturation, each group was subdivided into two subgroups according to the NiTi retreatment rotary system: Mtwo retreatment (Mtwo-R) file subgroup and ProTaper-UR subgroup-both instrumented with Mtwo-R files. Teeth were scanned with a microcomputed tomography before and after obturation.
\end{abstract}

Results: Residual filling material was observed in $100 \%$ of the specimens after retreatment. No difference was found between Mtwo-R and ProTaper-UR systems $(p>0.05)$. The RSA was more effectively removed from dentin walls than AH Plus Jet $(p<0.05)$, with no difference to MTA Fillapex $(p>0.05)$. Thus, teeth obturated with RSA required less operative time to be retreated (both, $p<0.05$ ).

Conclusion: ProTaper-UR and Mtwo-R systems were effective in removing the filling materials after instrumentation, but they could not eliminate them completely. Moreover, teeth obturated with silicone-based sealer RSA showed less residual filling material in dentin walls compared to the epoxy resin-based sealer (AH Plus Jet), which exhibited no difference compared to the salicylate resin-based sealer (MTA Fillapex). Teeth obturated with silicon-based sealer also required less operative time to be retreated despite the NiTi rotary retreatment system tested.

\footnotetext{
${ }^{1,3}$ Postgraduate Student, ${ }^{2}$ Assistant Professor

${ }^{4,5,7}$ Professor, ${ }^{6}$ Associate Professor

${ }^{1-5,7}$ Department of Restorative Dentistry, Endodontic Division São José dos Campos Dental School, State University of São Paulo, Brazil

${ }^{6}$ Department of Restorative Dentistry, Operative Dentistry Division, São José dos Campos Dental School, State University of São Paulo, Brazil

Corresponding Author: Frederico Canato Martinho, Assistant Professor, Department of Restorative Dentistry, Endodontic Division São José dos Campos Dental School, State University of São Paulo Brazil, Eng Francisco José Longo, 777 São José dos Campos São Paulo, Brazil, CEP 12245-000, Phone: (55) 1239479400 e-mail: Frederico.martinho@fosjc.unesp.br
}

Keywords: NiTi retreatment system, Retreatment, Root canal, Sealer.

How to cite this article: Moreira CS, Martinho FC, Coelho MPB, Júnior LRMC, da Silva EG, Torres CRG, Gomes APM. Cone-beam Computed Tomographic Analysis: Comparison of the Efficacy of Two Rotary Retreatment Systems for Removal of Filling Material from Primary Teeth Obturated with Contemporary Endodontic Sealers. World J Dent 2015;6(3):129-137.

Source of support: Nil

Conflict of interest: None

\section{INTRODUCTION}

The aim of endodontic retreatment is the complete removal of the filling material and decontamination of the root canal system, providing an adequate morphology for a new root canal filling. In order to attempt to remove the filling material completely, numerous techniques have been proposed, including stainless steel hand files, use of adjunctive solvents and/or ultrasonic means, reciprocating systems, and nickel titanium (NiTi) rotary systems $^{1-22}$ (Table 1).

Among the NiTi rotary systems, ProTaper-UR (Dentsply/Maillefer, Ballaigues, Switzerland) 1-14,16,18,21,22 and Mtwo retreatment (Mtwo-R) file (VDW, Munich, Germany $)^{7,10,12,14,19}$ are the most commonly used ones for removal of root canal filling materials. These systems present distinction in the file design regarding spiral blade, helical formation, anatomical configurations, and number of files. Particularly, ProTaper-UR system has three instruments (i.e. D1-30/0.09-16 mm, D2-25/0.08$18 \mathrm{~mm}$, and D3-20/0.07-22 mm), whereas Mtwo-R system has two instruments (i.e. R1-15/0.05 and R2-25/0.05), both with $21 \mathrm{~mm}$ length. ${ }^{11}$ The limited ability of NiTi rotary retreatment systems in removing filling material from dentin walls optimally has been demonstrated by previous investigations. ${ }^{3,7,12-14}$

Besides the technical difficulties in the retreatment, the type (prime constituents) of endodontic sealer used for obturation is also of concern. Adhesion to dentin walls ${ }^{6}$ and penetrability into dentin tubules ${ }^{23}$ implicate on an optimal cleansing of the dentin walls during retreatment. 


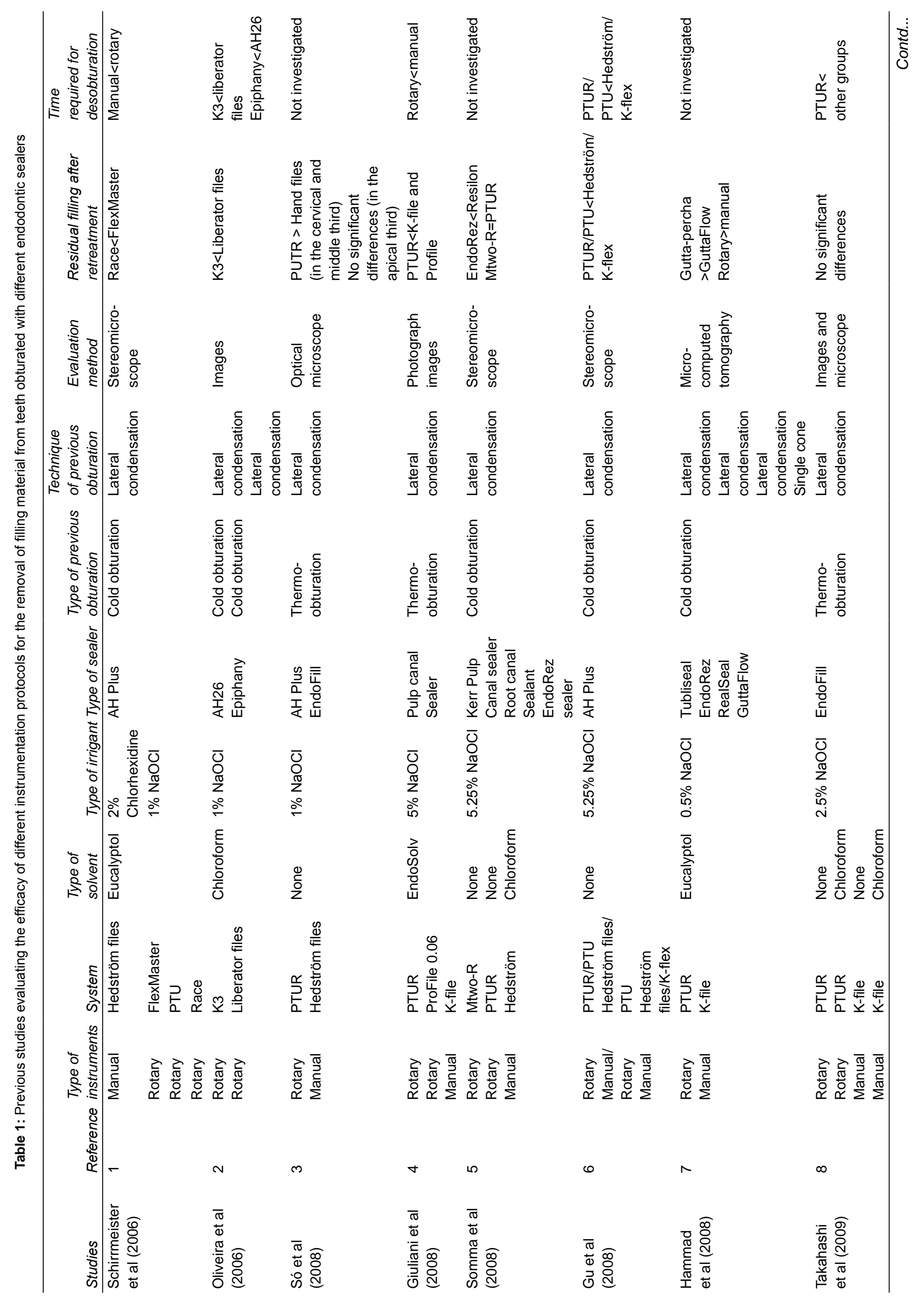



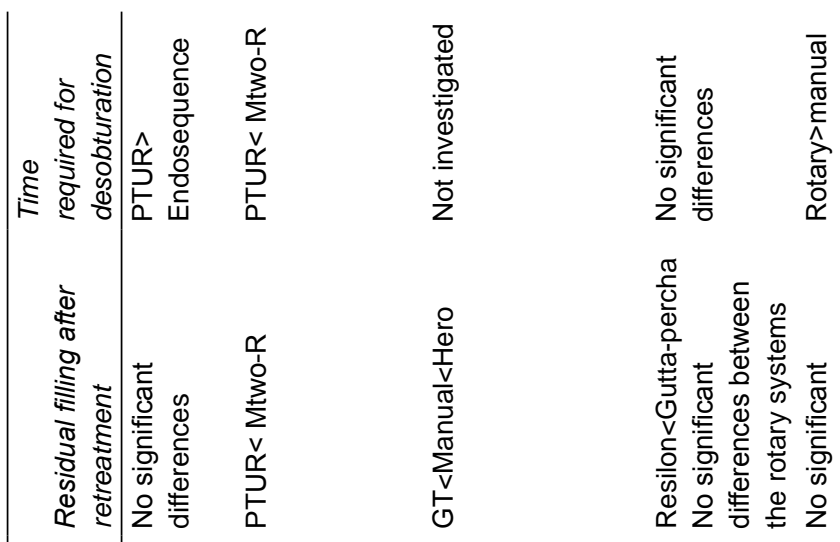

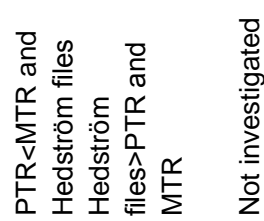

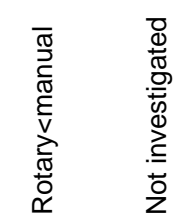

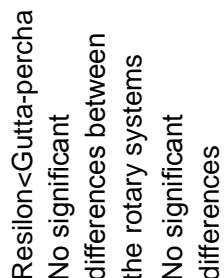

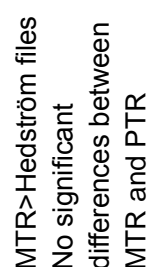

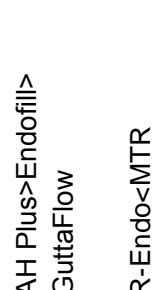

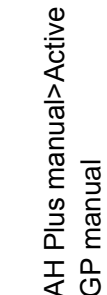

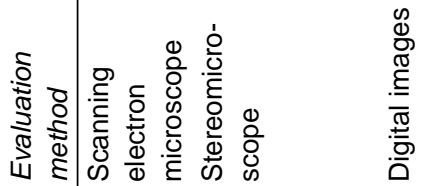

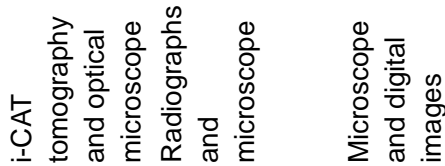

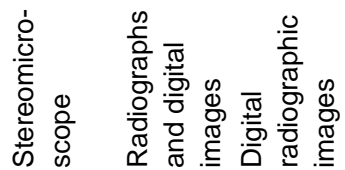

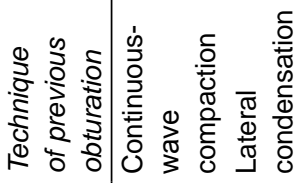

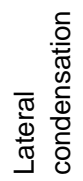

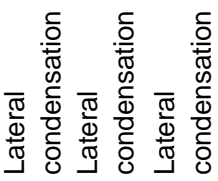

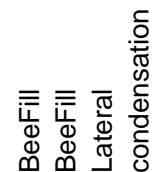

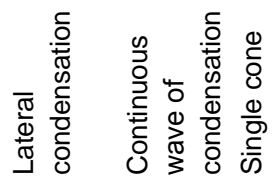

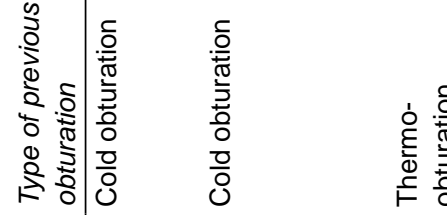

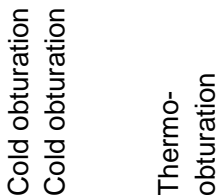

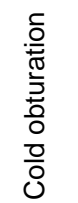

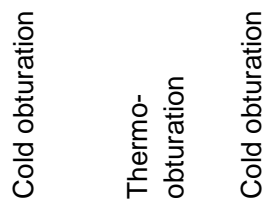

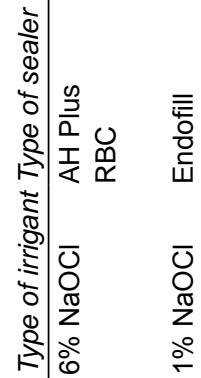

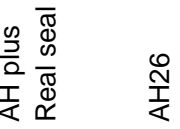

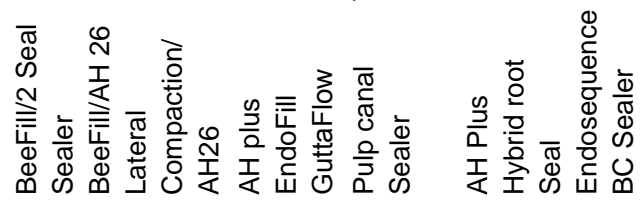

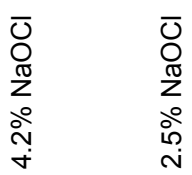

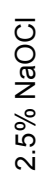

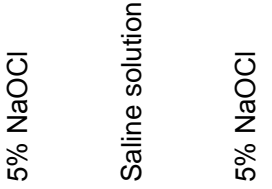

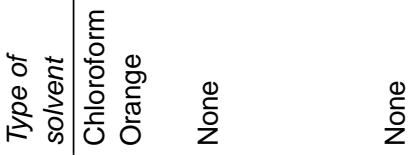

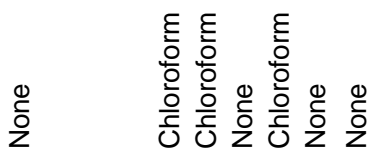

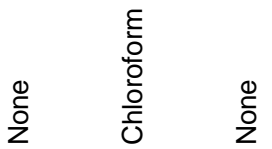

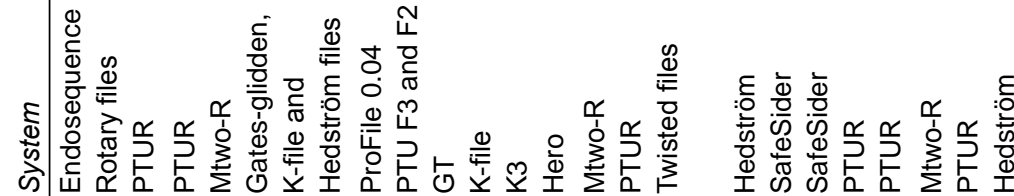
के

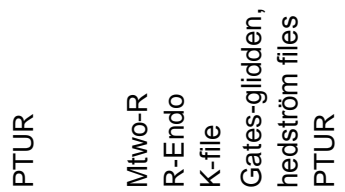

¿

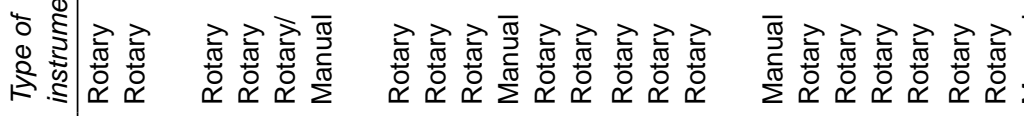

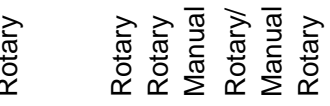

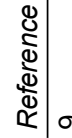

离

우

$\exists$

ㄱำ $\stackrel{\mathfrak{m}}{\rightarrow}$

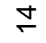

노 $\quad$ 국

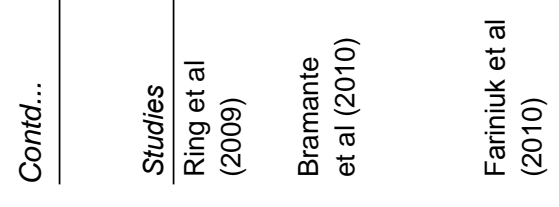

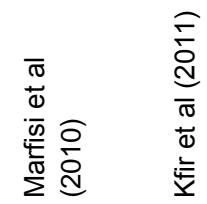

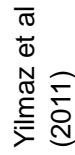

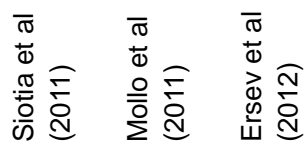




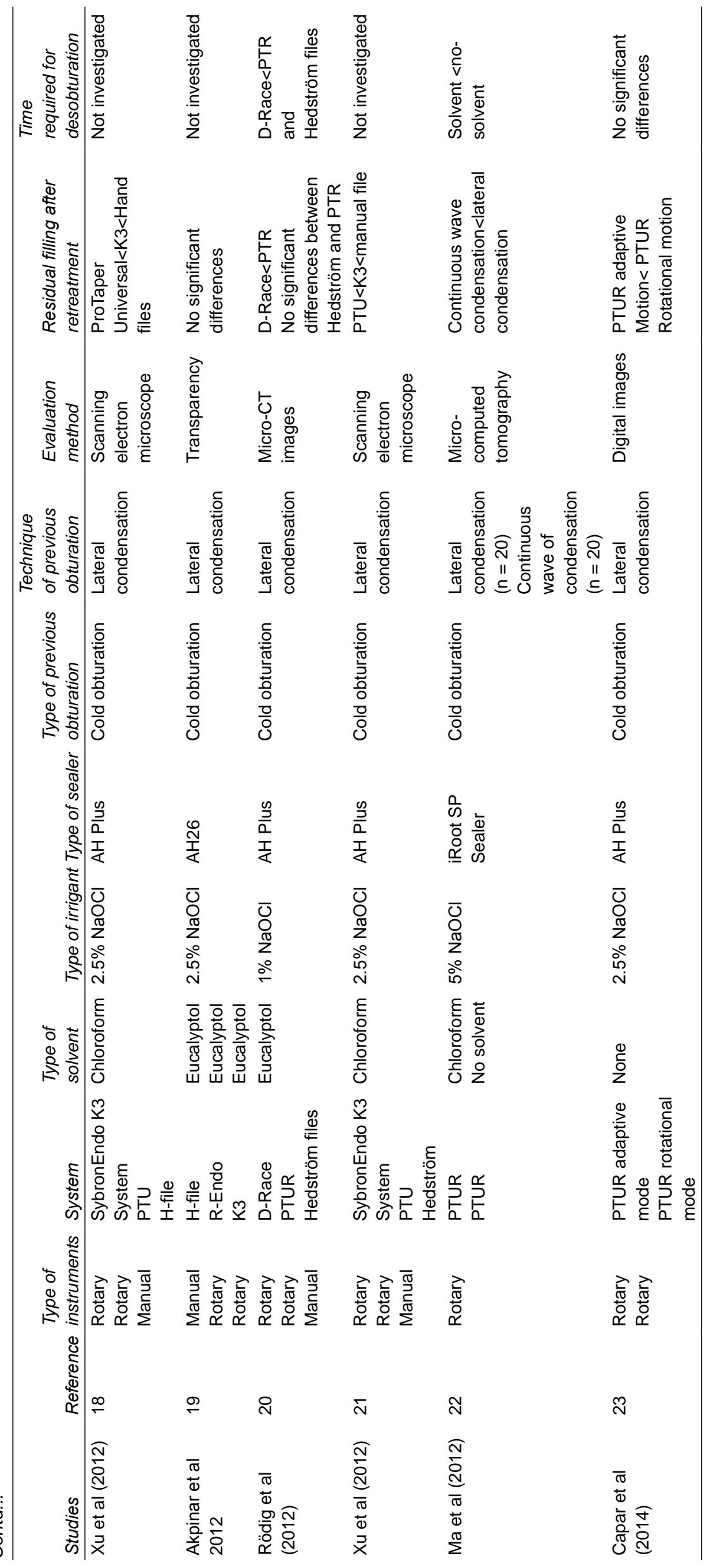


A wide variety of contemporary endodontic sealers have been introduced in the endodontic community, including mineral trioxide aggregate (MTA) Fillapex (Angelus Soluções Odontológicas, Londrina PR, Brazil), RoekoSeal (Dental Products, Langenau, Germany), and AH Plus Jet (Dentsply De Trey, Konstanz, Germany). ${ }^{24-27}$ Mineral trioxide aggregate Fillapex is a salicylate resin-based sealer with MTA as additional component, ${ }^{27}$ which was developed in an attempt to combine the physicochemical properties of an endodontic sealer with the excellent biological properties of MTA. Alternatively, RoekoSeal is a sealer based on silicone, which is a biocompatible material $^{24}$ exhibiting suitable physical properties necessary for an endodontic sealer, such as high $\mathrm{pH}$, contributing to its antibacterial activity, ${ }^{28}$ and little apoptotic effect on the cells exposed to it. ${ }^{24,25}$ A third choice is the AH Plus Jet (Dentsply De Trey, Konstanz, Germany), a methacrylate resin-based sealer with epoxy resin that is currently used as a root canal filling material and whose formulation is the same as that of the AH Plus sealer, with its cytotoxicity decreasing at longer setting times. ${ }^{24,25,29}$

The cone-beam computed tomography (CBCT) is a technology with different applications in different fields of dentistry. In endodontic research, CBCT technology has been frequently used for study of root canal anatomy and recently for assessment of changes in root canal morphology after instrumentation. ${ }^{30,31}$ It was shown that three-dimensional (3D) quantitative evaluation of residual filling material in root canal retreatment is also possible by using CBCT. ${ }^{12}$

Overall, the present study has used CBCT to evaluate the efficacy of two different NiTi rotary retreatment systems for removal of filling material from teeth obturated with contemporary endodontic sealers. The operative time required for removal of root filling materials was also evaluated.

The null hypothesis tested was that there are no differences in the removal of filling material from teeth obturated with contemporary endodontic sealers promoted by Mtwo-R and ProTaper-UR systems.

\section{METHODS}

\section{Specimen Preparation}

Sixty extracted mature human mandibular premolars (obtained from the department of surgery at the College of Dentistry of São José dos Campos) presenting fully formed apices, single canal without sharp curvature, absence of calcification and internal resorption were used. The crowns were sectioned with a doublesided diamond disk (Microdont Micro Precision Machining Ltd. São Paulo, Brazil) to obtain roots with
$16 \pm 0.5 \mathrm{~mm}$ in length. For standardization, the specimens were selected according to the diameter of their foraminal canals. Roots with foraminal diameter corresponding to K-type files from sizes \#15 to \#20 (Dentsply/Maillefer, Ballaigues, Switzerland) were selected and then equally distributed among the experimental groups according to the foraminal diameter.

\section{Root Canal Preparation}

working length was determined by inserting a size 15 K-file (Dentsply Maillefer) into the root canal until it was visible at the apical foramen and subtracting $1 \mathrm{~mm}$ from that measurement (working length of $\pm 15 \mathrm{~mm}$ ). A single operator instrumented all the root canals. Root canal preparation was done by using the Mtwo rotary system (MTwo, VDW, GmbH, Munich, Germany). Apical enlargement of the root canal was carried out by using files (up to \#40/0.04 sizes) coupled to an X-Smart Motor (Dentsply/Maillefer Ind. Com Ltda., RJ, Brazil) with 16:1 reduction and operating at speed of $300 \mathrm{rpm}$ and torque of $2 \mathrm{~N} / \mathrm{cm}$. Irrigation was performed with $5 \mathrm{ml}$ of $2.5 \%$ sodium hypochlorite (Asfer Indústria Química Ltda., SP, Brazil) between each instrument. After completing the instrumentation, the canal was irrigated with $10 \mathrm{ml}$ of $5 \% \mathrm{NaOCl}$ for 5 minutes, followed by $17 \%$ ethylenediaminetetraacetic acid (Asfer Indústria Química Ltda, São Caetano do Sul, São Paulo, Brazil) for 3 minutes. Next, the canals were washed with $10 \mathrm{ml}$ of saline solution (Glicolabor Pharmaceuticals Ind. Ltd., Ribeirão Preto, São Paulo, Brazil) and dried with paper points (Tanari, Manaus, Amazonas, Brazil).

\section{Root Canal Filling}

The teeth were randomly divided into three groups according to the sealer to be used for obturation: AH Plus Jet (Dentsply/De Trey GmbH, Konstanz, Germany), MTA Fillapex (Angelus, Londrina, PR, Brazil) and RoekoSeal Automix (Dental Products, Langenau, Germany) (all, $\mathrm{n}=20$ ). Their chemical composition, manufacturer and physical properties are detailed in Table 2. The teeth of each group were filled with the respective sealer and gutta-percha (Dentsply Maillefer) by using the cold lateral condensation technique. Excess filling material was removed and the cervical access was sealed with temporary restorative material (Cavit, ESPE Dental Seefeld, Germany). All specimens were stored at $100 \%$ humidity and $37^{\circ} \mathrm{C}$ for 30 days.

Before scanning, the teeth were fixed in a silicone impression material for the standardization of the CBCT images. Scanning of the teeth was performed with i-CAT system at $0.25 \mathrm{~mm}$ of voxel resolution and $6.00 \mathrm{~cm}$ of field of view (FOV) and analyses were done by using Xoran 
Table 2: Sealers tested and their chemical composition, manufacturer and physical properties*

\begin{tabular}{|c|c|c|c|c|}
\hline \multirow[t]{2}{*}{ Sealers } & \multirow{2}{*}{$\begin{array}{l}\text { Chemical composition } \\
\text { Salicylate resin, diluting resin, natural } \\
\text { resin, bismuth trioxide }\end{array}$} & \multirow{2}{*}{$\begin{array}{l}\text { Manufacturer } \\
\text { Angelus, Londrina, } \\
\text { Brazil }\end{array}$} & \multicolumn{2}{|c|}{ Physical properties } \\
\hline & & & Working time & 35 minutes \\
\hline & Nanoparticulated silica, MTA, pigments & & Flow capacity & $27.66 \mathrm{~mm}$ \\
\hline \multirow[t]{6}{*}{ MTA Fillapex } & & & Setting time & 130 minutes \\
\hline & & & Optical density & $77 \%$ \\
\hline & & & Solubility & 0.1 \\
\hline & $\begin{array}{l}\text { Paste A: diepoxide, calcium tungstate, } \\
\text { zirconium oxide }\end{array}$ & & Working time & 4 hours \\
\hline & Silica, iron oxide pigments & & Flow capacity & $36 \mathrm{~mm}$ \\
\hline & Paste B: 1-adamantane & & Setting time & 8 hours \\
\hline \multirow[t]{4}{*}{ AH Plus Jet } & $\begin{array}{l}\text { Amine, N,N-dibenzyl-5-oxa- } \\
\text { nonandiamine-1,9, TCDdiamine, }\end{array}$ & $\begin{array}{l}\text { Dentsply De Trey, } \\
\text { (Konstanz, Germany) }\end{array}$ & Optical density & 13.6 mm/mm Al \\
\hline & $\begin{array}{l}\text { calcium tungstate, zirconium oxide, aerosil } \\
\text { silica, silicone oil }\end{array}$ & & Solubility & $0.31 \%$ \\
\hline & Polydimethylsiloxane & & Working time & 15 to 30 minutes \\
\hline & Silicone oil & & Flow capacity & Not provided \\
\hline \multirow[t]{3}{*}{ RoekoSeal Automix } & Paraffin oil & & Setting time & 45 to 50 minutes \\
\hline & Zirconium dioxide & $\begin{array}{l}\text { Roeko, Langenau, } \\
\text { Germany }\end{array}$ & Optical density & Not provided \\
\hline & Hexachloroplatinic acid & & Solubility & 0 to $0.05 \%$ \\
\hline
\end{tabular}

*Composition according to information provided by the manufacturers

software (Xoran Technologies, USA) and Image Tool for Windows 3.0, (Las Vegas, Nevada, USA) for obtaining the total area of the root canal.

\section{Root Canal Retreatment}

Each group was subdivided into two subgroups according to the NiTi rotary system to be used for filling removal (10 canals for each subgroup): Mtwo-R subgroup, instrumented with Mtwo-R files (VDW, Munich, Germany); and ProTaper-UR subgroup: instrumented with ProTaper-UR files (Dentsply/Maillefer, Ballaigues, Switzerland). The coronal filling was removed to allow access to the entrance of the canal. To soften the filling material, the cold lateral condensation was removed according to the retreatment rotary system tested. For the Mtwo-R system, the root fillings were removed by using the R1 and R2 instrument activated by the same electric engine adjusted to $2 \mathrm{~N} / \mathrm{cm}$ torque and 300-rpm speed according to the manufacturer's instructions. The file worked with brushstroke movements against the canal walls in a crown-down direction until reaching the WL. No solvent was used. For the ProTaper UR system, the root fillings were removed by using D1, D2, and D3 retreatment instruments activated by an electric engine (X-Smart; Dentsply/Maillefer) adjusted to $2 \mathrm{~N} / \mathrm{cm}$ torque and 500-rpm speed and producing a brushing action against the canal walls in a crown-down direction until reaching the WL. D1 instrument worked in the cervical third, D2 in the middle third, and D3 in the entire working length, according to the manufacturer's instructions. No solvent was used. In each withdrawal, the instruments were wiped with gauze to remove adherent filling material and debris.

The canals were irrigated with $1 \% \mathrm{NaOCl}$ between instruments in the two groups. Removal of the filling material was judged complete when no more gutta-percha/ sealer could be seen on the last instrument used, the canal walls were smooth, the irrigating solution presented itself clean (without waste) after flushing the root canal, and no filling material could be detected inside the canal by the operating microscope (DF Vasconcelos SA, São Paulo, Brazil) at $12.5 \times$ magnification. The total time for removing the filling material was determined (in seconds) with a stopwatch during the action of each instrument inside the canal of each tooth.

\section{Cone-beam Computed Tomography Analyses}

After the removal procedure, each root was scanned again as described above. Then the images were analyzed with Xoran software (Xoran Technologies, USA) and Image Tool for Windows 3.0 for obtaining the area of filling material remaining in the root canal. The percentage volume of the remaining filling material in the canal walls was calculated according to the following equation: (Volume of remaining filling material/Volume of original filling material $) \times 100 \%$ $=$ volume $\%$ of remaining filling material.

The total time required for removing the filling material and the percentage volume of remaining filling material were analyzed by using three-way ANOVA, followed by post hoc Tukey's test $(\mathrm{p}<0.05)$. 


\section{RESULTS}

The mean (\%) and standard deviation of the remaining filling material present in dentin walls after retreatment are shown in Table 3. After retreatment, residual filling material was observed in $100 \%$ of the specimens $(60 / 60)$ (Table 3). According to the group tested, both Mtwo-R and ProTaper-UR systems were effective in removing the root filling material by up to approximately $90 \%$, as shown in Table 3. No difference was found when comparing Mtwo-R to ProTaper-UR systems in all groups tested ( $p>0.05)$. The three-way ANOVA analysis indicated that type of sealer $(p=0.001)$ was significantly implicated on the removal of root filling material. Particularly, the RoekoSeal Automix (RSA) sealer was more effectively removed than the AH Plus Jet one $(p<0.05)$ (Table 3). Thus, no differences were found between MTA Fillapex RSA, and AH Plus Jet (both, $p>0.05$ ). With regard to the total time required for retreatment, the silicone-based sealer (RSA) required less removal time than the epoxy resin-based (AH Plus Jet) and salicylate resin-based (MTA Fillapex) sealers $(\mathrm{p}<0.05)$ (Table 4$)$.

\section{DISCUSSION}

The data obtained in the present study revealed that ProTaper-UR and Mtwo-R systems were effective in removing the filling materials after instrumentation, but not in completely eliminating them. No difference was found when comparing both NiTi retreatment systems. Thus, the null hypothesis was accepted. Moreover, teeth obturated with silicone-based sealer (RSA) showed less residual filling material in dentin walls after retreatment than the epoxy resin-based sealer (AH Plus Jet), which exhibited no differences in relation to the salicylate resinbased sealer (MTA Fillapex). Moreover, teeth obturated with silicone-based sealer (RSA) required less time to be

Table 3: Distribution of the mean (\%) and standard deviation $( \pm S D)$ of remaining filling material present in dentin walls after retreatment

\begin{tabular}{lll}
\hline & MTwo- $R$ & ProTaper-UR \\
\hline AH Plus Jet & $26.96^{\mathrm{a}}( \pm 21.19)$ & $26.93^{\mathrm{a}}( \pm 11.95)$ \\
MTA Fillapex & $23.85^{\mathrm{ab}}( \pm 18.92)$ & $22.93^{\mathrm{ab}}( \pm 19.73)$ \\
RoekoSeal Automix & $9.40^{\mathrm{b}}( \pm 13.24)$ & $7.94^{\mathrm{b}}( \pm 9.01)$ \\
\hline
\end{tabular}

Different letters present statistical differences $(p<0.05)$

Table 4: Distribution of the mean and standard deviation ( \pm SD) values of operative time $(\mathrm{sec})$ required for removal of root filling materials in each group

\begin{tabular}{lll}
\hline & MTwo-R & ProTaper-UR \\
\hline AH Plus Jet & $411.3^{\mathrm{a}}( \pm 174.3)$ & $410.4^{\mathrm{a}}( \pm 115.9)$ \\
MTA Fillapex & $316.3^{\mathrm{a}}( \pm 52.1)$ & $315.3^{\mathrm{a}}( \pm 55.5)$ \\
RoekoSeal Automix & $167.0^{\mathrm{b}}( \pm 35.3)$ & $211.6^{\mathrm{b}}( \pm 32.5)$ \\
\hline
\end{tabular}

Different letters present statistical differences $(p<0.05)$ retreated than both AH Plus Jet and MTA Fillapex sealers, irrespective of the NiTi retreatment systems tested.

The retreatment of root-filled teeth is indicated when there is the persistence of disease resulting from microleakage, incomplete cleaning and shaping, technical shortcomings or complex anatomy. A quite few methods exist in endodontic literature evaluating the residual filling materials after retreatment, including radiographic assessment $^{1-22}$ (Table 1). Cone-beam computed tomographic analysis has been recently shown to be effective in giving a 3D evaluation of residual filling material in the root canal retreatment. ${ }^{12}$ Additionally, CBCT analysis has the advantage to be a noninvasive technique that allows detailed visualization of morphological features without requiring destruction of the specimen. ${ }^{12}$ Also, we have analyzed the effectiveness of Mtwo-R and ProTaper-UR systems for retreatment of roots filled with different endodontic sealers by using CBCT.

In the present study, no solvent was used in order to prevent any interference with the removability of the sealers and their evaluation ${ }^{3,6-8,10-14,16,22}$ (Table 1). In each withdrawal of the files, the instruments were wiped with gauze to remove adherent filling material and debris. Although solvents can be used to soften and dissolve gutta-percha in the root canal to facilitate its removal, reports on the effect of solvents on gutta-percha removal have been contradictory. ${ }^{7}$ Horvath et al (2009) found that solvents led to more gutta-percha and sealer remnants on root canal walls and inside dentinal tubules. It is postulated that the softening effect of chloroform on gutta-percha results in inadvertent distribution of guttapercha from the canal walls in the form of a film on the canal surface $1 .{ }^{8}$

The Mtwo-R and ProTaper-UR systems tested in the present study were not effective in removing traces of gutta-percha/sealer from the root canal walls completely. The limited ability of retreatment rotary systems to eliminate filling material has been demonstrated in the literature. ${ }^{3,7,19,20,21}$ Such limitations seem to be attributed to the anatomical configurations as well as to the rotary file design with spiral blade and helical formation, which makes the root canal to have a round cross-section, leaving substantial untouched areas on the buccal and lingual sides of a flat root canal.

Our results indicated that both Mtwo-R and ProTaperUR systems were effective in removing the root filling material by up to approximately $90 \%$. The high performance of these systems in removing filling material from dentin walls is reported elsewhere. ${ }^{5,8,11}$ Although both taper and size of the master apical file of the ProTaper-UR system (D3 file, 20/0.07) are larger than those of the Mtwo-R 
system (R2 file, 25/0.05), no significant difference was found between these systems regarding the removal of root filling materials. In fact, it is discussed that although the last instrument of the ProTaper-UR system (D3 file, 20/0.07) achieves the work length, it does not allow a complete cleaning action.., 7 The results obtained from different studies evaluating the efficacy of hand files and NiTi retreatment systems, including ProTaper-UR and Mtwo-R, for removal of filling materials (Table 1).

ProTaper-UR and Mtwo-R systems have been currently found to be safe for removal of filling materials from dentin walls, exhibiting no occurrence of file fracture as well as no perforation, blockage, or ledging of the root canal during retreatment. ${ }^{4,20}$ In contrast, some studies reported fracture of NiTi rotary files for retreatment during the removal procedure. ${ }^{2,12,21}$ Particularly, the active tip of the D1 file of the ProTaper-UR system seems to facilitate penetration of subsequent files without fracturing their tips. Moreover, the non-active tips of D2 and D3 files reduce the incidence of ledging, perforation, or stripping of the root canal during removal of filling materials compared to the Mtwo-R system, whose files have active tips (Mtwo R25/0.05 and Mtwo R15/0.05).

Besides the technical difficulties regarding the retreatment, the prime constituents of endodontic sealers used for obturation are also of concern in terms of optimal cleansing of the root canal systems. Three different contemporary sealers exhibiting different prime constituents were tested, namely, epoxy resin-based sealer (AH Plus Jet), silicone-based sealer (RSA), and salicylate resin-based sealer MTA Fillapex. Chemical compositions, manufacturing, and some physical properties, including working time, flow capacity, setting time, optical density and solubility, are shown in Table 2. Our results revealed that teeth obturated with silicone-based sealer (RSA) showed less residual filling material in dentin walls compared to epoxy resin-based sealer (AH Plus Jet), which exhibited no differences in relation to the salicylate resin-based sealer MTA Fillapex, irrespective of the NiTi rotary retreatment system used. It is worth to point out that one of the properties of endodontic sealers most probably related to their difficult removal is their adhesion to dentin walls $s^{6}$ and their penetrability into dentinal tubules, which improves retention of the core material by mechanical locking. ${ }^{21}$ In fact, previous studies evaluating the push-out bond strength values of endodontic sealers reported that AH Plus sealer (epoxy resin-based sealer) exhibits high mean values of bond strength to dentin walls compared to other sealers, ${ }^{4}$ including other sealers based on epoxy resin. ${ }^{20}$ With regard to the penetrability into dentinal tubules, there is a lack of information about the depth of penetration of MTA Fillapex and RSA, although the epoxy resin-based sealer displays a significant penetration in dentin walls of approximately $1.337 \mathrm{~mm} .{ }^{3,21}$ Additionally, Chandra et al (2012) showed that endodontic sealers exhibiting longer setting time, such as AH Plus, seem to exhibit a significantly deeper penetration into dentinal tubules. Therefore, the composition of the silicone-based RSA explains its ease to be removed from the root canal, leaving less residual and less time operating.

Several aspects including anatomical configurations of the root canals, selection of instrumentation technique, and prime constituents of endodontic sealers used for obturation as well as the use or non-use of solvents for retreatment are thought to be implicated on the removal time of root filling materials. ${ }^{1,2,4}$ In fact, teeth obturated with silicone-based sealer (RSA) required less time to be retreated compared to both AH Plus Jet and MTA Fillapex sealers, irrespective of the NiTi retreatment system used. Interestingly, despite the different number of files presented in the NiTi rotary retreatment systems tested (e.g. ProTaper-UR system has three instruments-D1, D2 and D3 files used at $500 \mathrm{rpm}$, whereas Mtwo-R system has two instruments-R1 and R2 files used at $300 \mathrm{rpm}$ ), no differences were found between these two systems regarding total time required for retreatment. It is worth to point out that the total operative retreatment time measured in this study consisted only of the operative action of each instrument inside the root canal, thus not involving switch of the files, which might have contributed to such results. Additionally, it might be speculated that the slight anatomical modifications in the tip and taper of the ProTaper-UR system (D1-30/0.09-16 mm, D2-25/0.08-18 mm, and D3-20/0.07) compared to the Mtwo-R system (R1-15/0.05 and R2-25/0.05), together with the higher speed of their endodontic files (ProTaperUR with $500 \mathrm{rpm}$ vs Mtwo-R with $300 \mathrm{rpm}$ ), might have favored the operative time of the former system despite the extra files used.

\section{CONCLUSION}

ProTaper-UR and Mtwo-R systems were effective in removing the filling materials after instrumentation, but without completely eliminating them. Moreover, teeth obturated with silicone-based sealer (RSA) showed less residual filling material in dentin walls than epoxy resinbased sealer (AH Plus Jet), which exhibited no differences in relation to the salicylate resin-based sealer MTA Fillapex. Moreover, teeth obturated with silicone-based sealer required less operative time for retreatment, irrespective of the NiTi rotary retreatment systems tested. 


\section{REFERENCES}

1. Oliveira DP, Barbizam JVB, Trope M, Teixeira FB. Comparison between gutta-percha and Resilon removal using two different techniques in endodontic retreatment. J Endod 2006;32:362-364.

2. Schirrmeister JF, Wrbas KT, Meyer KM, Altenburger MJ, Hellwig E. Efficacy of different rotary instruments for guttapercha removal in root canal retreatment. J Endod 2006; 32:469-472.

3. Gu LS, Ling JQ, Wei X, Huang XY. Efficacy of ProTaper Universal rotary retreatment system for gutta-percha removal from root canals. Int Endod J 2008;41:288-295.

4. Giuliani V, Cocchetti R, Pagavino G. Efficacy of ProTaper retreatment files in removing filling materials during root canal retreatment. J Endod 2008;34:1381-1384.

5. Hammad M, Qualtrough A, Silikas N. Three-dimensional evaluation of effectiveness of hand and rotary instrumentation for retreatment of canals filled with different materials. J Endod 2008;34:1370-1373.

6. Só MVR, Saran C, Magro ML, Vier-Pelisser FV, Munhoz M. Efficacy of ProTaper retreatment system in root canals filled with gutta-percha and two endodontic sealers. J Endod 2008; 34:1223-1235.

7. Somma F, Cammarota G, Plotino G, Grande NM, Pameijer $\mathrm{CH}$. The effectiveness of manual and mechanical instrumentation for the retreatment of three different root canal filling materials. J Endod 2008;34:466-469.

8. Takahashi CM, Cunha RS, De Martin AS, Fontana CE, Silveira CFM, Bueno CES. In vitro evaluation of the effectiveness of ProTaper universal rotary retreatment System for guttapercha removal with or without a solvent. J Endod 2009;35: 1580-1583.

9. Ring J, Murray PE, Namerow KN, Moldauer BI, GarciaGoldoy F. Removing root canal obturation materials: a comparison of rotary file systems and re-treatment agents. J Am Dent Assoc 2009;140:680-688.

10. Bramante CM, Fidelis NS, Assumpção TS, Bernardineli N, Garcia RB, Bramante AS, et al. Heat release, time required, and cleaning ability of MTwo R and ProTaper universal retreatment systems in the removal of filling material. J Endod 2010;36:1870-1873.

11. Fariniuk LF, Westphalen VPD, Silva-Neto UX, Carneiro E, Baratto Filho F, Fidel SR, et al. Efficacy of five rotary systems versus manual instrumentation during endodontic retreatment. Braz Dent J 2011;22:294-298.

12. Marfisi K, Mercade M, Plotino G, Duran-Sindreu F, Bueno R, Roig M. Efficacy of three different rotary files to remove gutta-percha and Resilon from root canals. Int Endod J 2010;43:1022-1028.

13. Siotia J, Acharya SR, Gupta SK. Efficacy of ProTaper retreatment system in root canals obturated with gutta-percha using two different sealers and guttaflow. Int J Dent 2011;2011:1-5.

14. Yilmaz Z, Karapinar SP, Ozcelik B. Efficacy of rotary NiTi retreatment systems in root canals filled with a new warm vertical compaction technique. Dent Mater J 2011;36:948-953.

15. Akpinar K, Altunbaş D, Kuş tarci A. The efficacy of two rotary NiTi instruments and $\mathrm{H}$-files to remove gutta-percha from root canals. Med Oral Patol Oral Cir Bucal 2012;17: 506-511.

16. Ersev H, Yilmaz B, Dinçol ME, Daglaroglu R. The efficacy of ProTaper universal rotary retreatment instrumentation to remove single gutta-percha cones cemented with several endodontic sealers. Int Endod J 2012;45:756-762.

17. Kfir A, Tsesis I, Yakirevich E, Matalon S, Abramovitz I. The efficacy of five techniques for removing root filling material: microscopic versus radiographic evaluation. Int Endod J 2012;45:35-41.

18. Ma J, Al-shaw AJ, Shen Y, Gao Y, Yang Y, Zhang C, et al. Efficacy of ProTaper rotary retreatment system for gutta-percha removal from oval root canals: a micro-computed tomography study. J Endod 2012;38:1516-1520.

19. Mollo A, Botti G, Goldoni NP, Randellini E, Paragliola R, Chazine $\mathrm{M}$, et al. Efficacy of two NiTi systems and hand files for removing gutta-percha from root canals. Int Endod J 2012;45:1-6.

20. Xu L, Zhang L, Zhou X, Wang R, Deng W, Huang D. Residual filling material in dentinal tubules after gutta-percha removal observed with scanning electron microscopy. J Endod 2012;38:293-296.

21. Rödig T, Hausdörfer T, Konietschke F, Dullin C, Hahn W, Hülsmann M. Efficacy of D-race and ProTaper universal retreatment $\mathrm{NiTi}$ instruments and hand files in removing gutta-percha from curved root canals-a micro-computed tomography study. Int Endod J 2011;45:580-589.

22. Capar ID, Arslan H, Ertas H, Gök T, Saygili G. Effectiveness of ProTaper universal retreatment instruments used with rotary or reciprocating adaptive motion in the removal of root canal filling material. Int Endod J 2014; in press.

23. Mamootil K, Messer HH. Penetration of dentinal tubules by endodontic sealer cements in extracted teeth and in vivo. Int Endod J 2007;40:873-881.

24. Lodiene G, Morisbak E, Bruzell E, Ørstavik D. Toxicity evaluation of root canal sealers in vitro. Int Endod J 2008;41: 72-77.

25. Karapınar-Kazandag M, Bayrak ÖF, Yalvaç ME, Ersev H, Tanalp J, Sahin F, et al. Cytotoxicity of 5 endodontic sealers on L929 cell line and human dental pulp cells. Int Endod J 2011;44:626-634.

26. Silva EJNL, Santos CC, Zaia AA. Long-term cytotoxic effects of contemporary root canal sealers. J Appl Oral Sci 2013;21:43-47.

27. CarpenterMT,SidowSJ,Lindsey KW, Chuang A,McPhersonJC. Regaining apical patency after obturation with gutta-percha and a sealer containing mineral trioxide aggregate. J Endod 2014;40:588-590.

28. Morgental RD, Vier-Pelisser FV, Oliveira SD, Antunes FC, Cogo DM, Kopper PM. Antibacterial activity of two MTAbased root canal sealers. Int Endod J 2011;44:1128-1133.

29. Cotti E, Petreucic V, Re D, Simbula G. Cytotoxicity evaluation of a new resin-based hybrid root canal sealer: an in vitro Study. J Endod 2014;40:124-128.

30. Peters OA, Laib A, Rüegsegger P, Barbakow F. Threedimensional analysis of root canal geometry by high-resolution computed tomography. J Dent Res 2000;79:1405-1409.

31. Paqué F, Balmer M, Attin T, Peters OA. Preparation of oval-shaped root canals in mandibular molars using nickeltitanium rotary instruments: a micro-computed tomography study. J Endod 2010;36:703-707. 